\title{
Tuberculosis: renewed challenge in Brazil
}

\author{
Valdes Roberto Bollela ${ }^{[1]}$
}

[1]. Divisão de Moléstias Infecciosas e Tropicais, Departamento de Clínica Médica, Faculdade de Medicina de Ribeirão Preto, Universidade de São Paulo, Ribeirão Preto, SP, Brasil.

Tuberculosis (TB) continues to be an important public health problem, affecting millions of persons per year. Although it can be treated effectively, it remains the major cause of deaths due to infectious diseases worldwide ${ }^{1}$. The treatment of TB is affordable and highly effective, yet it remains a serious cause of illness and death, so serious as to have been declared a global emergency in 1993. TB is principally a disease of poverty, with $95 \%$ of cases and $98 \%$ of deaths occurring in developing countries ${ }^{2}$. Between 2000 and 2016, TB treatment alone averted an estimated 44 million deaths among human immunodeficiency virus (HIV)-negative people and an additional 8.5 million deaths among HIV-positive people when TB treatment was supported by antiretroviral therapy (ART) ${ }^{1}$. Approximately 6.3 million new TB cases were reported in 2016, which is equivalent to $61 \%$ of the estimated 10.4 million incidence, and the latest treatment outcome data showed a global success rate of $83 \%$, similar to the recent years ${ }^{1}$. Despite clear improvements in the cure rate, a significant gap still exists when considering misdiagnosed and non-diagnosed TB cases, mainly among drug-resistant tuberculosis (DR-TB) and vulnerable population. To shorten this gap, the World Health Assembly approved, in May 2014, the new Global TB Elimination Strategy that aims at reducing mortality and incidence of TB in all countries, targeting the indicators currently observed in high-income countries. This new strategy is based on three pillars: 1) integrated patient-centered care and prevention; 2) bold policies and support systems; and 3) intensification of research and incorporation of new technologies ${ }^{3}$. The article published in this issue of the Revista $d a$ Sociedade Brasileira de Medicina Tropical presents an integrated perspective on how Brazilian players, policies, and actions toward TB elimination should be aligned around these three pillars, for example, decentralized actions for primary care (Pillar 1), the higher proportion of TB treatment completion in municipalities with high family allowance coverage (Bolsa Familia Program), and Rede TB, the Brazilian TB Research Network (Pillar 3). The authors emphasized the consensus among researchers in basic, translational, and clinical areas about the need for interaction between the academy, government, and industry. Therefore, the way to move toward this direction includes clinical research

Corresponding author: Dr. Valdes Roberto Bollela.

e-mail: bollela@gmail.com

Received 9 February 2018

Accepted 16 February 2018 (explanatory and pragmatic clinical trials) with operational/ implementation research to analyze the clinical and budgetary impact on patients and the local health system.

The emergence of DR-TB is an increasing threat to TB control with more than 600,000 new cases that are resistant to rifampicin tuberculosis (RRTB); 490,000 of whom had multidrug-resistant tuberculosis (MDR-TB) ${ }^{4}$. In 2016, coverage of testing for rifampicin resistance was $33 \%$ for new and $60 \%$ for previously treated TB patients. Molecular tests recommended by the World Health Organization (Xpert@ MTB/ RIF or Genotype ${ }^{\circledR}$ MTBDRplus) are the fastest way to obtain information about rifampicin and isoniazid susceptibility profile, which makes a huge difference. Phenotypic drug susceptibility tests are the gold standard, but not accessible in a reasonable time to support fast and reliable clinical decision making. For sure, these new technologies should be tested in pragmatic clinical trials, but will be required to design and implement studies to answer these questions ${ }^{5}$. Early diagnosis is the turning point to control DR-TB. This induces building capacity to deal with these challenging situations. A retrospective study analyzing the number of reported cases from 2000 to 2012, in São Paulo State, showed that the number of diagnosed/reported DR-TB and the cure rates had been increasing, while the mortality decreased from $30 \%$ (2000-2003) to $8 \%$ (2009-2012). The same trend was observed in a single reference center where death rate dropped from $37.5 \%(2000-2005)$ to $3.4 \%(2006-2012)^{6}$.

\section{REFERENCES}

1. World Health Organization (WHO). Global tuberculosis report 2017. Geneva: WHO; 2017.

2. Grange JM, Zumla A. The global emergency of tuberculosis: what is the cause? Perspect Public Health. 2002;122(2):78-81.

3. Uplekar M, Weil D, Lonnroth K, Jaramillo E, Lienhardt C, Dias HM, et al. for WHO's Global TB Programme. WHO's new End TB Strategy. Lancet 2015;385(9979):1799-801.

4. World Health Organization (WHO). WHO treatment guidelines for drug-resistant tuberculosis (2016 update). WHO/HTM/TB/2016.04. Geneva. WHO; 2016.

5. World Health Organization (WHO). Moving research findings into new WHO policies. Available from: http://www.who.int/tb/dots/ laboratory/policy/en/index4.html

6. Bollela VR, Puga FG, Moya MJ, Andrea M, Oliveira MLV. A decade trend of multidrug-resistant tuberculosis in São Paulo State, Brazil. Rev Inst Med Trop Sao Paulo. 2016;58:77-84. 